\title{
Efeitos de diferentes níveis de matéria orgânica no solo e de inóculo sobre a interação planta-Meloidogyne spp. e a produção massal de Pasteuria penetrans ${ }^{1}$
}

Fábio Ramos Alves ${ }^{1,2}$, Leandro Grassi De Freitas ${ }^{3}$, Paulo Roberto Pala Martinelli ${ }^{3}$, Renata Maria Strozi Alves Meira $^{4}$, Silamar Ferraz 3 , Antônio Jacinto Demuner ${ }^{5}$, Eduardo Euclydes De L. Borges ${ }^{6}$, Waldir de Cintra Jesus Júnior ${ }^{2}$

${ }^{1}$ Parte da Tese de Doutorado em Fitopatologia do primeiro autor desenvolvida na Universidade Federal de Viçosa, Departamentos de ${ }^{3}$ Fitopatologia, ${ }^{4}$ Biologia Vegetal, ${ }^{5}$ Química e ${ }^{6}$ Engenharia Florestal, Universidade Federal de Viçosa, 36571-000, Viçosa, MG, Brasil. ${ }^{2}$ Departamento de Produção Vegetal do CCA, Universidade Federal do Espírito Santo.

Autor para correspondência: fabioramosalves@yahoo.com.br

Data da chegada: 07/08/2006. Aceito para publicação em: 23/04/2007.

\section{RESUMO}

Alves, F.R.; Freitas, L.G.; Martinelli, P.R.P.; Meira, R.M.S.A., Ferraz, S., Demuner, A.J., Borges, E.E. de L., Jesus Júnior, W.C. Efeitos de diferentes níveis de matéria orgânica no solo e de inóculo sobre a interação planta-Meloidogyne spp. e a produção massal de Pasteuria penetrans. Summa Phytopathologica, v.33, n.4, p.397-401, 2007.

Foram estudados os efeitos de quatro proporções de esterco de curral no solo, $0,20,33$ e $50 \%(\mathrm{~V}: \mathrm{V})$, e três níveis de inóculo de Meloidogyne spp. $(3.000,6.000$ e $9.000 \mathrm{~J} 2$ por planta) na concentração de fenóis em raízes de tomateiro, no desenvolvimento das fêmeas, nas células gigantes induzidas por esses patógenos e na infecção e reprodução de Pasteuria penetrans. O experimento foi conduzido em casa-de-vegetação, em delineamento inteiramente ao acaso com doze repetições, sendo avaliado 50 dias após a inoculação das plantas. O tamanho médio das fêmeas do nematóide foi maior quando as plantas foram inoculadas com $3.000 \mathrm{~J} 2$. Maior percentual de fêmeas infectadas por $P$. penetrans foi observado quando não se utilizou esterco no substrato ou quando as plantas foram inoculadas com $3.000 \mathrm{~J} 2$. As plantas inoculadas com $9.000 \mathrm{~J} 2$ e cultivadas no substrato com $20 \%$ de esterco foram as que produziram mais endósporos. A concentração de fenóis nas raízes aumentou à medida que se acrescentou esterco de curral ao substrato. As células gigantes de plantas cultivadas no substrato com 33 e $50 \%$ de esterco apresentaram menores número, tamanho e quantidade de núcleos. O aumento da proporção de esterco de curral ao substrato causou aumento nas concentrações de fenóis nas raízes, fato que foi deletério às células gigantes, prejudicial ao desenvolvimento do nematóide e à reprodução de $P$. penetrans.

Palavras-chave adicionais: Pasteuria penetrans, nematóides das galhas, controle biológico.

\section{ABSTRACT}

Alves, F.R.; Freitas, L.G.; Martinelli, P.R.P.; Meira, R.M.S.A., Ferraz, S., Demuner, A.J., Borges, E.E. de L., Jesus Júnior, W.C. Effects of cow manure levels in the soil and inoculum concentration on the plant-Meloidogyne spp. interaction and on the mass production of Pasteuria penetrans. Summa Phytopathologica, v.33, n.4, p.397-401, 2007.

The effects of four different proportions of cow manure, 0,20 , 33 and $50 \%(\mathrm{~V}: \mathrm{V})$ and three Meloidogyne spp. inoculum levels $(3,000$; 6,000 and $9,000 \mathrm{~J} 2$ per plant) on the phenol concentration in the tomato roots, in the nematode female development, the giant cells induced by the nematode and on the reproduction of Pasteuria penetrans were investigated. The experiment was carried out in greenhouse, in a completely randomized design with twelve replicates, and evaluated 50 days after inoculation. The size of nematode females was higher when the plants were inoculated with 3,000 J2. Higher proportion of females infected by $P$. penetrans was observed when the plants were cultivated in the substrate without cow manure or when plants were inoculated with 3,000 J2. Plants inoculated with $9,000 \mathrm{~J} 2$ and cultivated on substrate with $20 \%$ of cow manure yielded more endospores. The phenolic content in the roots increased as higher proportions of cow manure were used in the substrate or when the plants were inoculated with the highest number of nematodes. The giant cells of plants cultivated on substrate with 33 and $50 \%$ of cow manure were less numerous, smaller and had less nuclei number, demonstrating the deleterious effect of organic amendments on the giant cells, on the nematodes and on the $P$. penetrans reproduction.

Additional Keywords: Pasteuria penetrans, root-knot nematode, biological control.

A bactéria Pasteuria penetrans (Thorne) Sayre \& Starr (20) é um parasito obrigatório com potencial para o controle biológico de fitonematóides em condições de campo (8) devido às várias características desejáveis que apresenta $(2,6)$. Na ausência de meios artificiais para a produção de $P$. penetrans, o método utilizado para sua multiplicação é o de Stirling \& Wachtel (24), no qual tomateiros são inoculados com $5.000 \mathrm{~J} 2$ de Meloidogyne sp., com endósporos aderidos à cutícula. Para uma possível aplicação prática dessa bactéria em nível de campo, sua produção ‘in vivo' deve ser otimizada visando o aumento da produção de endósporos de $P$. penetrans por planta (12, 19,21). Uma hipótese a ser estudada é a da adição de esterco de curral ao substrato para proporcionar esse aumento, pois plantas cultivadas em solo orgânico se desenvolvem mais vigorosamente, com sistemas radiculares maiores e se tornam capazes de tolerar uma carga maior de 
nematóides (12). Como a produção de $P$. penetrans depende do número de fêmeas infectadas por planta $(21,24)$, a utilização de esterco possibilitaria a inoculação de maior número de juvenis com endósporos aderidos, pois haveria mais sítios de penetração e a planta melhor nutrida poderia nutrir melhor o nematóide, e consequentemente a bactéria, resultando em maior produção de endósporos por planta. Entretanto, se a matéria orgânica for prejudicial ao desenvolvimento do nematóide, a produção de $P$. penetrans pode ser afetada negativamente (23). Entre os compostos sintetizados pelas plantas, os fenóis são conhecidos por atuarem na resistência a patógenos $(10,23)$ e adição de esterco pode elevar o nível de fenóis nas raízes da planta hospedeira (1), deformando as células gigantes e engrossando suas paredes celulares, o que tornaria a planta mais resistente aos nematóides $(3,16,19)$.

Este trabalho objetivou avaliar como a adição de esterco de curral ao substrato afeta a produção de $P$. penetrans através de alterações dos níveis de fenóis nas raízes, da integridade das células gigantes e do tamanho das fêmeas do nematóide, assim como a interação entre níveis de esterco, níveis de inóculo de nematóides e número de endósporos da bactéria produzidos por planta.

\section{MATERIAL E MÉTODOS}

Foram preparadas misturas de solo, areia e esterco de curral de forma a se obter $0,20,33$ e $50 \%$ de esterco no substrato. O solo, areia e esterco foram homogeneizados manualmente e tratados com brometo de metila na dose de $200 \mathrm{~cm}^{3} / \mathrm{m}^{3}$ de substrato.

Uma população mista de espécies de Meloidogyne com aproximadamente $60 \%$ de $M$. incognita (Kofoid e White) Chitwood e $40 \%$ de $M$. javanica (Treub) Chitwood foi obtida de plantas de tomate cv. Santa Clara cultivadas em casa-de-vegetação. Ovos dos nematóides foram obtidos pela técnica de Hussey \& Barker (1973) modificada por Boneti \& Ferraz (4), colocados em câmaras de eclosão e mantidos a $26{ }^{\circ} \mathrm{C}$ para obtenção dos juvenis de segundo estádio (J2). Os J2 eclodidos foram coletados diariamente e mantidos em água com borbulhamento de ar até serem utilizados nos experimentos. A quantificação dos J2 foi feita em câmaras de Peters sob estereoscópio.

Para a obtenção de inóculo de $P$. penetrans, plantas de tomateiro cv. Santa Clara foram cultivadas em solo infestado com $P$. penetrans e $\mathrm{J} 2$ de $M$. javanica foram depositados ao redor das plantas. Após 70 dias da inoculação, as plantas foram removidas dos vasos, as fêmeas foram retiradas das raízes sob estereoscópio, transferidas para tubos tipo Eppendorf e maceradas para a obtenção de uma suspensão de endósporos, cuja quantificação foi feita em câmara de Neubauer.

Após a obtenção do inóculo de Meloidogyne spp. e de $P$. penetrans, $30 \mathrm{~mL}$ de suspensão aquosa contendo $10.000 \mathrm{~J} 2$ e 1 x $10^{6}$ endósporos da bactéria foi agitada em agitador orbital a $180 \mathrm{rpm}$ por 30 minutos. A suspensão contendo cerca de cinco endósporos aderidos por J2 foi mantida a $8^{\circ} \mathrm{C}$ para interromper o processo de adesão. Posteriormente, plantas de tomateiro cv. Santa Clara com 20 dias de idade foram inoculadas com 3.000, 6.000 ou $9.000 \mathrm{~J} 2$ com até 72 horas de idade. Segundo Silva et al. (22), o número de endósporos de $P$. penetrans aderidos em $M$. incognita e $M$. javanica foi aproximadamente igual, de modo que populações mistas de Meloidogyne spp. podem ser empregadas para multiplicação de $P$. penetrans.

$\mathrm{O}$ delineamento estatístico foi o inteiramente casualizado em esquema fatorial 3 x 4 (três níveis de inóculo de Meloidogyne spp. e quatro proporções de esterco de curral), com doze repetições, sendo que, em quatro destas, as plantas foram inoculadas com os nematóides sem a presença da $P$. penetrans para determinação dos níveis de fenóis nas raízes das plantas e para a caracterização estrutural das raízes. O experimento foi realizado de fevereiro a abril de 2003 .

Cinqüenta dias após a inoculação, os sistemas radiculares de oito repetições foram lavados e pesados para a obtenção do peso da matéria fresca por planta (PMF) e avaliados quanto ao número de galhas por planta (NG). Trinta fêmeas por sistema radicular foram medidas com auxílio de um tubo de imagem acoplado a um microscópio de luz. Cada fêmea foi desenhada, a imagem digitalizada e a área determinada com o uso do software Quant 1.0.1 (25). Determinou-se também a porcentagem de fêmeas infectadas por $P$. penetrans esmagando-as e observando-as em microscópio de luz. Em seguida, foi determinado o número de endósporos por fêmea (NEF) avaliando-se dez fêmeas do nematóide, de cada sistema radicular. Foi feita a secagem das raízes em estufa de ventilação forçada a $70^{\circ} \mathrm{C}$ por 72 horas para determinação da matéria seca da raiz por planta (PMS), e moagem de cada sistema radicular individual em micro moinho (General Eletric A-C mot), para obtenção de um pó fino de raiz (24). Finalmente, o número de endósporos por planta (NEP) foi determinado em câmara de Neubauer.

A caracterização estrutural das raízes e determinação do teor de fenóis em raízes de tomateiro foram feitas conforme métodos descritos a seguir:

\section{Caracterização estrutural das raízes de tomateiro}

Foram retiradas dez galhas radiculares por sistema radicular, das quais segmentos de $0,5 \mathrm{~cm}$ foram fixadas em formaldeído - ácido acético - álcool $\left(\mathrm{FAA}_{50}\right)$ e estocadas em etanol 70\% (13). Para obtenção de cortes histológicos, procedeu-se à inclusão em parafina utilizando-se a série etílico-butílica para a desidratação (13). Os cortes transversais seriados, de $14 \mathrm{~mm}$ de espessura, foram corados com azul de astra e fucsina básica (9) por 5 e 20 minutos respectivamente, e as lâminas montadas com resina sintética (bálsamo do Canadá). As observações e as ilustrações foram obtidas em um fotomicroscópio (Olympus BX50) equipado com sistema Optronic enginering DEI. À partir das imagens obtidas, quantificou-se o número de núcleos nas primeiras trinta células gigantes de cada tratamento. Também foram determinadas as áreas das células gigantes em noventa células das plantas de cada tratamento, que foram previamente desenhadas, as imagens digitalizadas e a área determinada a partir do software Quant 1.0.1 (25).

\section{Determinação do teor de fenóis em raízes de tomateiro}

A análise fotoquímica foi feita através de espectrofotômetro de duplo feixe Hitachi U-2000, sendo realizadas três leituras por amostra, no Departamento de Química da UFV. Para a obtenção e preparação das raízes para a extração do tanino (fenóis totais), utilizou-se a técnica de Mueller-Hervey (9).

Na preparação da amostra para leitura de absorvância, foi pipetado $0,5 \mathrm{~mL}$ do extrato em balão volumétrico de $10 \mathrm{~mL}$, ao qual foram adicionados 7,5 $\mathrm{mL}$ de água destilada, $0,5 \mathrm{~mL}$ do reagente Folin-Denis e $1 \mathrm{~mL}$ de solução saturada de carbonato de sódio, sendo completado o volume para $10 \mathrm{~mL}$ com água destilada. Após adição dos regentes, esperou-se 30 minutos para leitura de absorbância em $760 \mathrm{~nm}$.

Para atender as pressuposições da ANOVA, as características PMF, PMS, NG e NEP foram transformados para $\sqrt{x+0,5}$. Os dados foram submetidos a ANOVA e as médias dos dados qualitativos comparadas pelo teste de Tukey, $5 \%$ de probabilidade, utilizando-se o programa SASâ versão 6.12.

\section{RESULTADOS E DISCUSSÃO}

Com base na tabela 1 , verifica-se que a única característica avaliada onde houve interação significativa foi o número de endósporos por planta (NEP). Com exceção do tamanho de fêmeas (TF), todas as 
Tabela 1. Quadrados médios e coeficientes de variação (CV) das características PMF (peso da matéria fresca), PMS (peso da matéria seca), NG (número de galhas), \% FI (porcentagem de fêmeas infectadas por Pasteuria penetrans), NEP (número de endósporos por planta), CF (concentração de fenóis), NC (número de células gigantes), TCG (tamanho de células gigantes) e TF (tamanho de fêmeas de $M$. incognita).

\begin{tabular}{|c|c|c|c|c|c|c|c|c|c|}
\hline FV & PMF & PMS & NG & $\% \mathrm{FI}$ & NEP & $\mathrm{CF}$ & $\mathrm{NC}$ & TCG & $\mathrm{TF}$ \\
\hline Substrato & $0,107 * *$ & $0,912 * *$ & $303,5 * *$ & $1007,67 *$ & $3,979 * *$ & $0,003 *$ & $131,833 * *$ & $0,759 * *$ & $2,25^{\mathrm{ns}}$ \\
\hline Nível de inóculo de $M$. incognita (NI) & $0,004^{\mathrm{ns}}$ & $0,039^{\mathrm{ns}}$ & $79,33 *$ & $1026,67 *$ & $1,159 *$ & $0,003^{\mathrm{ns}}$ & - & - & $2,633 *$ \\
\hline Substrato x NI & $0,008^{\mathrm{ns}}$ & $0,086^{\mathrm{ns}}$ & $25,57^{\mathrm{ns}}$ & $367,288^{\text {ns }}$ & $8,409 * *$ & $0,002^{\text {ns }}$ & - & - & $0,676^{\text {ns }}$ \\
\hline CV $(\%)$ & 9,55 & 25,95 & 28,9 & 34,2 & 80,42 & 2,68 & 43,35 & 67,47 & 13,30 \\
\hline
\end{tabular}

* significativo ao nível de $5 \%$ de probabilidade

**significativo ao nível de $1 \%$ de probabilidade

ns não significativo

características foram significativas para o fator substrato e, em relação ao fator nível de inóculo do nematóide, as características número de galhas (NG), porcentagem de fêmeas infectadas por P. penetrans $(\% \mathrm{FI})$ e tamanho de fêmeas (TF) foram significativos.

Menores PMF, PMS e NG $(\mathrm{P} \leq 0,05)$ foram observados no substrato com $50 \%$ de matéria orgânica (Tabela 2). As galhas são resultantes do aumento do número de células nas raízes e, conseqüentemente, sua massa. À medida que o nível de inóculo subiu de 3.000 para $9.000 \mathrm{~J} 2$, observou-se aumento do NG (Figura 1). Esses resultados estão de acordo com aqueles observados por Gomes (12). Quando o substrato continha $50 \%$ de matéria orgânica, menor número de galhas foi formado, o que pode ser conseqüência da atuação de compostos tóxicos aos nematóides produzidos pela matéria orgânica. Essas observações estão em concordância com aquelas feitas por Lazarovits et al., (14); Nico et al., (15); Riegel et al., (18) e Viaene \& Abawi (26).

O tamanho das fêmeas e o percentual de fêmeas infectadas por $P$. penetrans foram maiores quando se utilizou o menor nível de inóculo do nematóide, ou seja, 3.000 J2 (Figuras 2 e 3). Isso, possivelmente, por haver menor competição por sítios de alimentação e mais alimento disponível aos nematóides, que se desenvolvem melhor, permitindo que $P$. penetrans também tenha maior possibilidade de se desenvolver e completar seu ciclo (5). Maior percentual de fêmeas infectadas por $P$. penetrans $(\mathrm{P} \leq 0,05)$ foi observado quando se utilizou substrato sem matéria orgânica do que nos substratos com 33 e 50\% de matéria orgânica (Tabela 2), o que pode ser explicado pelo fato de as raízes das plantas cultivadas em substrato com maiores proporções de matéria orgânica terem apresentado maiores teores de fenóis $(\mathrm{P} \leq 0,05)$ (Tabela 2), o que possivelmente dificultou a penetração dos J2 com $P$. penetrans nas raízes. Alam et al. (1) observaram aumento nos níveis de fenóis de 12,96 a $151,85 \%$ em raízes de tomateiro quando

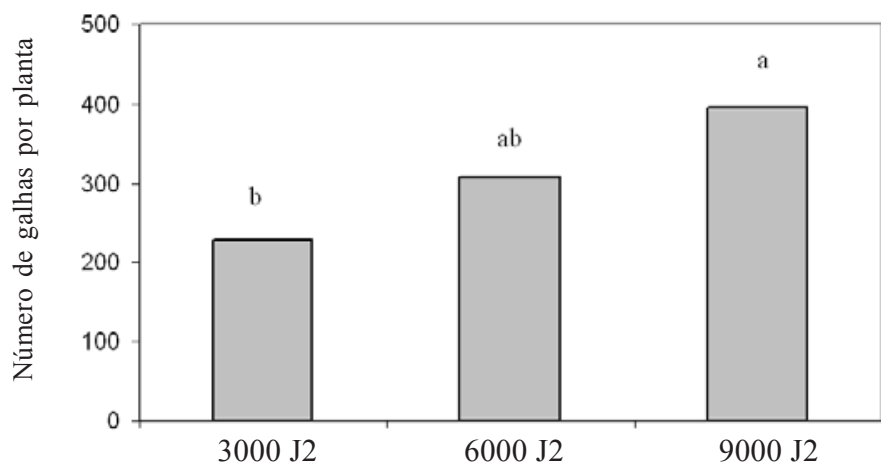

Figura 1. Número de galhas por sistema radicular de tomateiro cv. Santa Clara inoculado com 3.000, 6.000 ou 9.000 juvenis de segundo estádio (J2) de Meloidogyne spp.

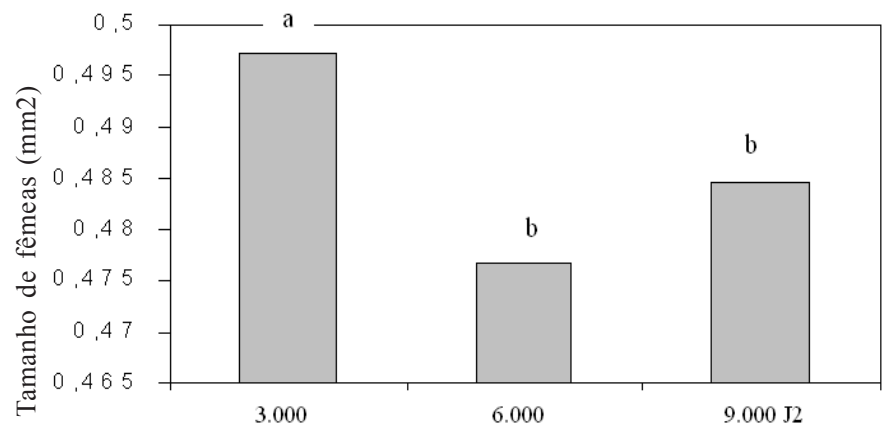

Figura 2. Tamanho de fêmeas de Meloidogyne spp. parasitando tomateiros cv. Santa Clara inoculados com 3.000, 6.000 ou 9.000 juvenis de segundo estádio (J2) do nematóide.

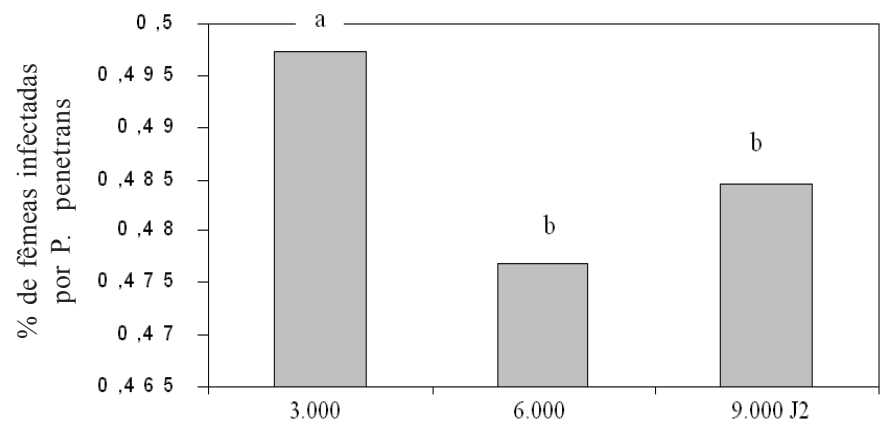

Figura 3. Percentual de fêmeas de Meloidogyne spp. infectadas por Pasteuria penetrans quando plantas de tomateiros cv. Santa Clara foram inoculados com $3.000,6.000$ ou 9.000 juvenis de segundo estádio (J2) do nematóide.

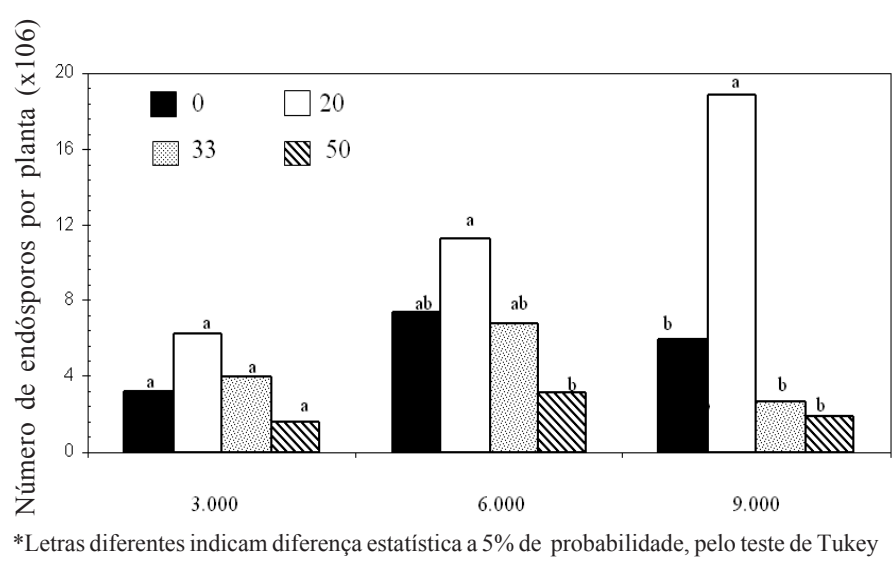

Figura 4. Número de endósporos de Pasteuria penetrans por sistema radicular de tomateiro cv. Santa Clara inoculado com 3.000, 6.000 ou 9.000 juvenis de segundo estádio (J2) de espécies de Meloidogyne e cultivado em substratos com $0,20,33$ ou $50 \%$ de esterco de curral adicionado ao substrato. 
Tabela 2. Efeito de diferentes proporções de esterco no substrato sobre PMF e PMS (peso da matéria fresca e seca de raízes de tomateiro, respectivamente); NG (número de galhas por sistema radicular); \% FI (percentual de fêmeas infectadas por Pasteuria penetrans); NEP (número de endósporos de $P$. penetrans por planta); CF (concentração de fenóis em raízes de tomateiro); NC (número de núcleos por célula) e TCG (tamanho das células gigantes).

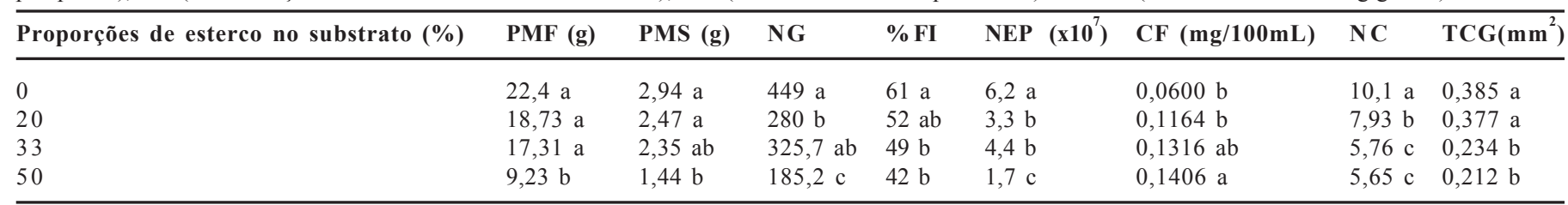
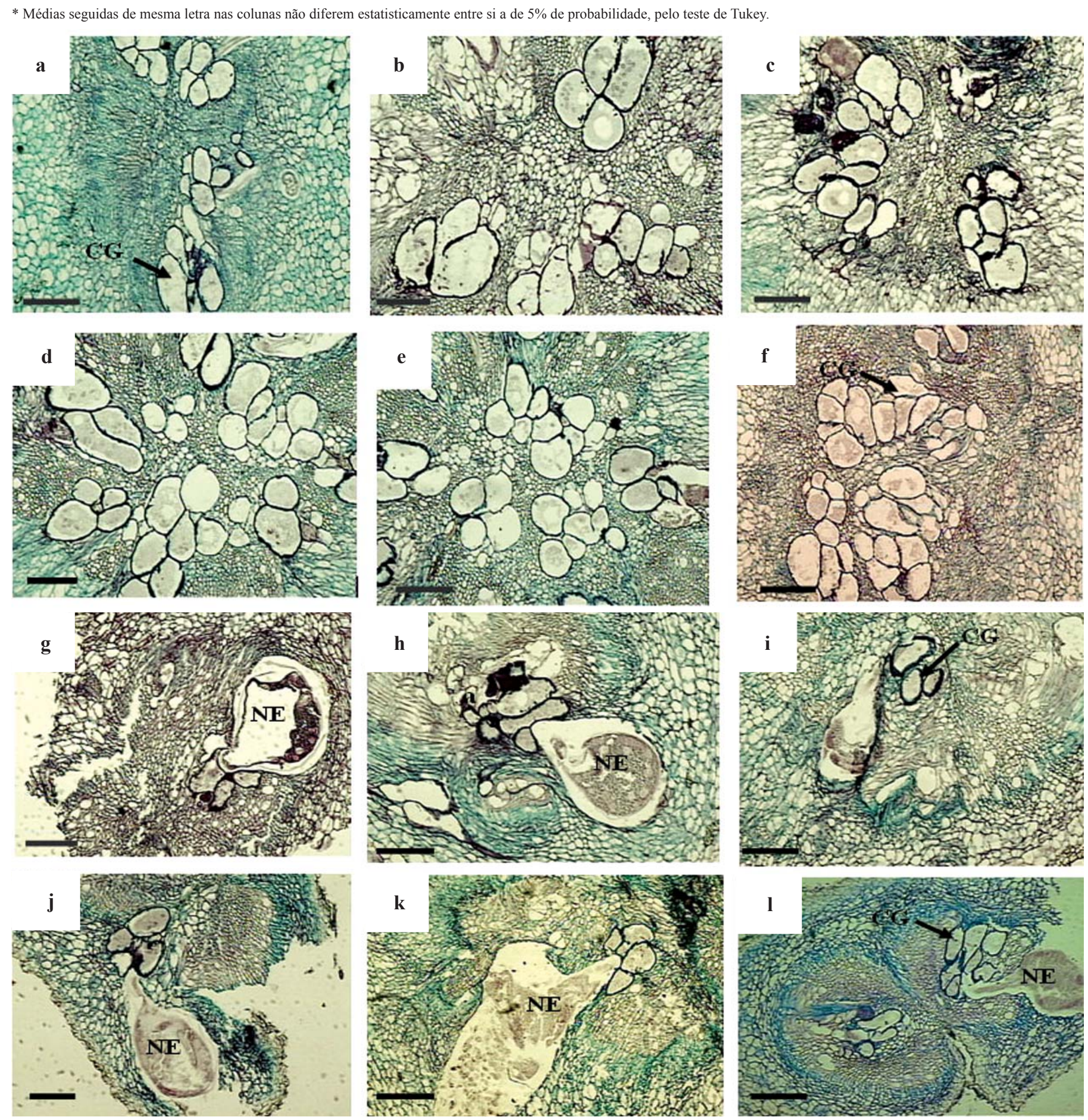

Figura 5. Cortes transversais de galhas de raízes de tomateiro cv. Santa Clara parasitadas por Meloidogyne spp. Células gigantes bem desenvolvidas em raízes de plantas cultivadas em substrato com $0 \%$ ou $20 \%$ de esterco de curral no substrato $(0 \%=\mathrm{a}-\mathrm{c}) ;(20 \%=\mathrm{d}-\mathrm{f})$. Células gigantes menores, em menor número e deformadas, presentes em raízes de plantas cultivadas em substrato com $33 \%$ ou $50 \%$ de esterco de curral no substrato $(33 \%=\mathrm{g}-\mathrm{i}) ;(50 \%=\mathrm{j}$ 1). $\mathrm{CG}=$ Células gigantes, $\mathrm{NE}=$ nematóides. Barras $=100 \mu \mathrm{m}$. 
essas plantas foram cultivadas em substratos que receberam resíduos orgânicos, e essas maiores concentrações de fenóis estavam relacionadas com menor penetração do sistema radicular por M. incognita. Segundo Giebel (11), entre as substâncias produzidas pelas plantas que estão envolvidas na resistência a fitopatógenos, os compostos fenólicos são os que merecem maior destaque. Alguns autores afirmam que há uma correlação positiva entre resistência de plantas a fitopatógenos e conteúdo de fenóis nos tecidos radiculares $(10,17)$. De fato, compostos fenólicos estimulam a síntese do ácido indol-acético (AIA)-oxidase, o que favorece a degradação da auxina, comprometendo a formação das células gigantes (10). Os relatos de Giebel (10) são confirmados nesse estudo pelas observações feitas nas células gigantes das plantas cultivadas em substratos que receberam 33 e 50\% de matéria orgânica. Os sítios de alimentação (Figura 5 e Tabela 2), foram menores, menos numerosos e com deformações, com paredes mais espessas e com menor número de núcleos se comparados àqueles de plantas cultivadas nos substratos com 0 e $20 \%$ de matéria orgânica. Alguns autores relataram que plantas resistentes a Meloidogyne spp. podem apresentar células gigantes com vacúolos menores, menor desenvolvimento, menor número de núcleos, escurecimento do citoplasma e depósito de calose em células adjacentes àquelas invadidas pelos nematóides $(3,7,16$, 19), o que está em concordância com observações feitas nesse estudo.

Plantas inoculadas com $9.000 \mathrm{~J} 2$ e cultivadas no substrato com $20 \%$ de esterco apresentaram maior número de endósporos (Figura 4). A maior produção de endósporos quando se utilizou maior nível de inóculo de espécies de Meloidogyne está de acordo com os dados encontrados por Gomes (12), que observou que plantas inoculadas com $2.000 \mathrm{~J} 2$ permitiram multiplicação de $P$. penetrans de até 2,5 vezes superior àquelas que receberam $1.000 \mathrm{~J} 2$.

Com base nos resultados obtidos neste trabalho conclui-se que não é recomendada a incorporação das maiores proporções de esterco de curral ao substrato para a multiplicação da $P$. penetrans, porém o acréscimo das menores doses é desejável, pois resultou em maior produção de endósporos de $P$. penetrans por vaso.

\section{REFERÊNCIAS BIBLIOGRÁFICAS}

1. Alam, M.M.; Ahmad, M.; Khan A.M. Effect of organic amendments on the growth and chemical composition of tomato, eggplant and chilli and their susceptibility to attack by Meloidogyne incognita. Plant and Soil, Crauley, v.57, n.2-3, p.231-236, 1980.

2. Bird, A.F.; Brisbane, P.G.; Mcclure, S.G.; Dimber, R.W.L. Studies on the properties of the spores of some populations of Pasteuria penetrans. Journal of Invertebrate Pathology, Estados Unidos, v.55, n.2, p.169-178, 1990 .

3. Bleve-Zacheo, T.; Zacheo, G.; Melillo, M.T.; Lamberti, F. Ultrastructural aspects of the hypersensitive reaction tomato root cells resistant to Meloidogyne incognita. Nematologia Mediterrânea, Bari, v. 10, n.1, p.81-90, 1982.

4. Boneti, J.I.S.; Ferraz, S. Modificações do método de Hussey \& Barker para extração de ovos de Meloidogyne exigua em raízes de cafeeiro. Fitopatologia Brasileira, Brasília, v.6, n.3, p.533, 1981.

5. Cho, M.R.; Dickson, D.W.; Hewlett, T.E. Comparison of inoculation method, Meloidogyne spp., and different host plant for production of Pasteuria penetrans. Journal of Nematology, College Park, v.29, n.4, p.573-574, 1997.

6. Dutky, E.M.; Sayre, R.M. Some factors affecting infection of nematodes by the bacterial spore parasite Bacillus penetrans. Journal of Nematology, College Park, v.10, n.4, p. 285, 1978. (abstract).

7. Fonseca, H. S.; Ferraz L. C. C. B.; Machado, S.R. Comparative ultrastructure of rubber tree roots parasitized by Meloidogyne exí- gua and M. javanica. Nematologia Brasileira, Piracicaba, v. 27, n.2, p.199-206, 2003.

8. Freitas, L.G.; Neves, W.S.; Carmo, D.N.; Silva, G.S. First case of induction of soil suppressiveness to root-knot nematode by Pasteuria penetrans in large areas in the field in Brazil. In: Congresso Brasileiro de Nematologia, 22., 2000, Uberlândia. Anais, Uberlândia, 2000. p. 129.

9. Gerlach, D. Botanische mikrotechnik, eine einfuhrung. Georg thieme: Stuttgart, 1977. 311p.

10. Giebel, J. Phenolic content in roots of some solanaceae and its influence on IAA-oxidase activity as an indicator of resistance to Heterodera rostochiensis. Nematologica, Leiden, v.16, n.1, p.2232,1970 .

11. Giebel, J. Biochemical mechanisms of plant resistance to nematodes: A review. Journal of Nematology, College Park, v.6, n.4, p.175-184, 1974.

12. Gomes, C.B. Métodos para o aprimoramento da multiplicação de Pasteuria penetrans (Thorne) Sayre \& Starr “in vivo". 2001. 60f. Tese (Doutorado em Fitopatologia) - Universidade Federal de Viçosa, Viçosa, MG.

13. Johansen, D.A. Plant microtechnique. New York: McGraw-Hill, 1940. 523p.

14. Lazarovits, G.; Tenuta, M.; Conn, K.L. Organic amendments as a disease control strategy for soil borne diseases of high-value agricultural crops. Australasian Plant Pathology, Lorne, v.30, n.2, p.111$117,2001$.

15. Nico, A.I.; Jimenez-Diaz, R.M.; Castillo, P. Control of root-knot nematodes by composted agro-industrial wastes in potting mixtures. Crop Protection, Oxford, v.23, n.7, p.581-587, 2004.

16. Pedrosa, E.M.R.; Hussey, R.S.; Boerma, H.R. Cellular responses of resistant and susceptible soybean genotypes infected with Meloidogyne arenaria races 1 and 2 . Journal of Nematology, College Park v.28, n.2, p.225-232, 1996.

17. Pitcher, R.S.; Patrick, Z.A. Mountain, W.B. Studies on the hostparasite relations of Pratylenchus penetrans (Cobb) to apple seedlings. Nematologica, Leiden, v.5, p.309-314, 1960.

18. Riegel, C.; Fernandez, F.A.; Noe, J.P. Meloidogyne incognita infested soil amended with chicken litter. Journal of Nematology, College Park, v.28, n.3, p.369-378, 1996.

19. Rodrigues, A.K.; Freitas, L.G.; Azevedo, A.A.; Ferraz, S. Desenvolvimento de Pasteuria penetrans em Meloidogyne spp. parasitando diferentes espécies vegetais. Fitopatologia Brasileira, Brasília, v.28, n.3, p.267-272, 2003.

20. Sayre, R.M.; Starr, M.P. Pasteuria penetrans (ex Thorne, 1940) nom. rev., comb. n., sp. n., a mycelial and endospore-forming bacterium parasitic in plant parasitic nematodes. Proceedings of the Helminthological Society of Washington, Washington, v. 52 , p.149-165, 1985.

21. Sharma, R.D.; Stirling, G.R. In vivo mass production systems for Pasteuria penetrans. Nematologica, Leiden, v.37, p.483-484, 1991.

22. Silva, R. V.; Freitas, L.G.; Coutinho, M.M. Caracterização da espeficidade de uma população mista de Pasteuria penetrans utilizada no biocontrole de nematóides. In: Congresso Brasileiro de Fitopatologia, 36., 2003, Uberlândia. Anais, Uberlândia, 2003. p.377.

23. Singh, S.P.; Pant, V.; Khan, A.M. Saxena, S.K. Attractiveness of Meloidogyne incognita larvae to roots of tomato and changes in biochemical content of plants as affected by oilcakes and nematicides. Nematologia Mediterrânea, Bari, v.11, p.119-123, 1983.

24. Stirling, G.R.; Wachtel, M.F. Mass production of Bacillus penetrans for the biological control of root-knot nematodes. Nematologica, Leiden, v.26, p.308-312, 1980.

25. Vale, F.X.R. Do; Fernandes Filho, E.I.; Liberato, J.R.; Zambolim, L.. Quant - a software to quantify plant disease severity In: International workshop on plant disease epidemiology, 8., 2001, Ouro Preto. Ouro Preto: International Society of Plant Pathology, 2001. $160 \mathrm{p}$.

26. Viaene, N.M.; Abawi, G.S. Management of Meloidogyne hapla on lettuce in organic soil with sudangrass as a cover crop. Plant Disease, St. Paul, v.82, n.8, p.945-952, 1998. 